\title{
Geldpolitisches Kräftemessen
}

D as Vertrauen in den Dollar als internationale Leitwährung hat mit der Weltfinanz- und Wirtschaftskrise gelitten. Insbesondere China und Russland, die immense Dollarreserven halten, fordern Alternativen. Ebenso dokumentiert der jährliche Bericht der Europäischen Zentralbank zur internationalen Rolle des Euro vorsichtig die steigende internationale Bedeutung des Euro als Fakturierungs-, Wertaufbewahrungs-, Bank-, Anker-, Interventions- und Reservewährung. Auf den Weltwirtschaftsgipfeln reflektiert die Diskussion über ein multipolares Weltwährungssystem das angekratzte Image des Greenback. Der Missmut kommt in erster Linie von den aufstrebenden Volkswirtschaften. Deren Wirtschaftsentwicklung ist zwar dynamischer als die der Industrieländer, sie sind aber aufgrund des geringen Vertrauens in ihre Währungen für die Abwicklung des internationalen Waren- und Kapitalverkehrs auf eine internationale Währung angewiesen. Internationale Währungen sind Währungen großer Länder mit hohem Bruttoinlandsprodukt und dichten Handelsbeziehungen. Sie sind hinterlegt mit hoch entwickelten Finanzmärkten, die es erlauben, internationale Ersparnisse und Währungsreserven kostengünstig, vielfältig und risikolos zu investieren. Nachhaltige makroökonomische Stabilität ist notwendig, um Vertrauen zu schaffen. Netzwerkeffekte zementieren die Dominanz internationaler Währungen.

Genährt von historisch niedrigen Zinsen und explodierender Staatsverschuldung in den USA, mehren sich die Zweifel an der Stabilität des Dollars. China hat auf der Basis hoher Exportüberschüsse internationale Reserven im Wert von mehr als 2 Billionen US-\$ angehäuft, ein Großteil in Dollar. Sinken die USLeitzinsen, sieht sich die chinesische Regierung aus zwei Gründen zur Wechselkursstabilisierung und somit zum Ankauf von Dollar gezwungen. Erstens würde der Export als wichtiger Wachstumsmotor ausgebremst. Zweitens würden die Dollaranlagen gerechnet in chinesischen Yuan entwertet. Persistente Dollarabwertungserwartungen, wie sie durch nachhaltig niedrige US-Zinsen entstehen können, würden bei flexiblen Wechselkursen den Run aus dem Dollar in den Yuan beschleunigen. Ähnliches gilt für Rohstoffexporteure wie Russland. Da der Weltrohstoffhandel in Dollar denominiert ist, sind deren Währungen an den Dollar gebunden. Die Rohstoffeinkommen werden stabilisiert und Ersparnisse können zu geringen Transaktionskosten in den Dollarfinanzmärkten recycelt werden. Doch feste Wechselkurse halten den Wert der Auslandvermögen nur auf kurze Frist stabil, da mit den Devisenmarktinterventionen die inländische Geldmenge wächst. Durch Inflation, Finanzmarkt- und Immobilienblasen wird das Inlandsvermögen entwertet. China und Russland waren deshalb im Aufschwung vor der jüngsten Krise bemüht, die aus Devisenmarktinterventionen resultierende überschüssige Geldmenge durch sogenannte Sterilisierungsoperationen zumindest teilweise zu absorbieren. Doch mit unerwünschten Nebeneffekten: Wird wie in China durch erhöhte Mindestreserven zu künstlich niedrigen Zinsen sterilisiert, dann wird die Zinsstruktur fragmentiert und die Wirtschaftsstruktur verzerrt. Werden die Dollarerlöse wie im Fall von Russland direkt in einen Staatsfonds eingebracht, dann unterbleibt zwar die Geldmengenexpansion, aber es gibt ein Anlagerisiko. Insbesondere bei Finanzmarktkrisen in den Industrieländern kann es wie jüngst zu hohen Verlusten in den Aktien- und Immobilienportfolios kommen.

Aufgrund dieses Dilemmas hat China mahnend den Finger erhoben und zeigt Visionen von einer Weltwährungsordnung ohne den Dollar auf. Da die Finanzmärkte der aufstrebenden Volkswirtschaften unterentwickelt und mit hohen Transaktionskosten verbunden sind, stellen die eigenen Währungen keine Option dar, auch wenn China in bilateralen Geschäften mit Entwicklungsländern

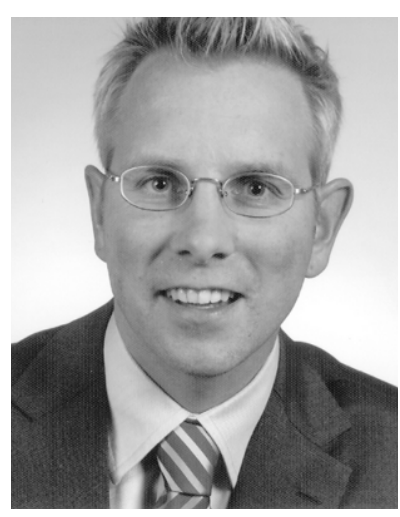

Gunther Schnabl 
den Yuan forciert. China hat deshalb einen Rohstoffstandard und die Sonderziehungsrechte des IWF ins Spiel gebracht. Doch diese Kunstwährungen sind ebenso wenig mit tiefen Kapitalmärkten hinterlegt und können deshalb weder Reserve- noch Ankerwährung sein. Da die Sonderziehungsrechte aber als Korb der vier wichtigsten internationalen Währungen (Dollar, Euro, Yen und Pfund) definiert sind, kann die Forderung Chinas als Drohung gesehen werden, sich schrittweise vom Dollar (hin zum Euro) zu entkoppeln. Russland hat es vorgemacht. Traditionell war der russische Handel und Kapitalverkehr dollarisiert und der Rubel einseitig an den Dollar gebunden. Das Gros der Reserven wurde in Dollar gehalten. Im Jahr 2005 wurde der Rubel erstmals gegenüber einem Währungskorb mit einem Eurogewicht von 10\% (Dollar 90\%) stabilisiert. Zudem wurde angekündigt, dass ein Eurogewicht von 50\% angestrebt werde. Diesem Ziel hat man sich schrittweise angenähert. Ebenso ist der Anteil des Euro an den Währungsreserven inzwischen höher als der des Dollar. Der partielle Verbleib beim Dollar spiegelt die Abhängigkeit von den dollarisierten Rohstoffmärkten wider. Für China ist die Abkehr vom Dollar aus drei Gründen schwieriger. Erstens würde die plötzliche Flucht des größten Halters von Dollarreserven einen Kollaps des Dollarkurses und des US-Finanzmarktes nach sich ziehen. Die verbleibenden Dollaranlagen Chinas würden entwertet und Chinas Export in die USA leiden. Zweitens sind in ganz Ostasien sowohl die Handels- und Finanzbeziehungen mit den USA als auch die innerostasiatischen Zahlungsströme dollarisiert. Eine Abkehr vom Dollar wäre deshalb nur graduell und koordiniert möglich, um die Wechselkursstabilität innerhalb Ostasiens sicherzustellen. Drittens, eine eigenständige währungspolitische Integration in Ostasien nach dem Muster Europas steckt in den Kinderschuhen. Derzeit erfüllt keine ostasiatische Währung einschließlich Yen und Yuan die Voraussetzungen für eine Leitwährung. Zudem würde der Weg zu einer gemeinsamen ostasiatischen Währung einen politischen Integrationsprozess erfordern, der derzeit aufgrund der Rivalität zwischen China und Japan nicht absehbar ist.

Es bleibt der Euro als einzige Alternative. Der institutionelle geldpolitische Rahmen in der EWU scheint im Lichte der Finanzmarktkrise stärker der Preisstabilität verpflichtet als in den USA, wo die Grenzen zwischen Zentralbank und Regierung zu verschwimmen scheinen. Sollten die Halter der Weltdollarreserven dieser Meinung sein, werden sie graduell trotz Netzwerkeffekten ihre Reserven von Dollar auf Euro umschichten. Dies könnte mit einer Anpassung der Wechselkursziele hin zu Währungskörben mit steigendem Eurogewicht verbunden sein. Für das Euroland wären die Aufwertung des Euro und Verluste für die Exportindustrien die Konsequenz. Langfristig würde das Eurogebiet von steigenden Seignioragegewinnen profitieren. Ob es so weit kommen wird, ist fraglich. Die USA werden nicht ohne Weiteres die internationale Führungsrolle ihrer Währung aufgeben. Eine merkliche Abkehr vom Dollar könnte als Signal für mehr geldpolitische Disziplin in den USA gewertet werden. Dies käme einer Rückkehr der Welt zu mehr geldpolitischer Stabilität gleich. Alternativ erhöht sich mit steigendem Aufwertungsdruck auf den Euro der Druck zu monetärer Expansion in der Europäischen Währungsunion. Die Inflationsraten im Eurogebiet würden gegen die USA konvergieren und damit der Anreiz zur Abkehr von der Weltleitwährung reduziert. Diese entspräche einem Gleichgewicht bei einem höheren Weltinflationsniveau. Die Frage um die zukünftige Weltleitwährung könnte deshalb durch ein geldpolitisches Kräftemessen zwischen Federal Reserve und Europäischer Zentralbank entschieden werden.

Gunther Schnabl ist Professor für Volkswirtschaftslehre und Leiter des Instituts für Wirtschaftspolitik der Universität Leipzig schnab/@wifa.uni-leipzig.de 